\title{
Subject-Based Information Retrieval System in Digital Libraries
}

\author{
Mohammad-Hossein Biglu1, Mostafa Ghavami2* \\ ${ }^{1}$ Basic Sciences Department, Paramedical Faculty, Tabriz University of Medical Sciences, Tabriz, Iran \\ ${ }^{2}$ Radiology Department, Paramedical Faculty, Tabriz University of Medical Sciences, Tabriz, Iran \\ Email: Biglu@tbzmed.ac.ir, *mostafa.ghavami@yahoo.com
}

Received 26 April 2016; accepted 24 July 2016; published 27 July 2016

Copyright (C) 2016 by authors and Scientific Research Publishing Inc.

This work is licensed under the Creative Commons Attribution International License (CC BY).

http://creativecommons.org/licenses/by/4.0/

(c) (i) Open Access

\begin{abstract}
Objective: Information visualization is the study of interactive depictions of abstract and data to strengthen the human cognition. Designing an appropriate information visualization system may be very useful technique for scholars, who intent to get scientific information from digital libraries. The objective of current study was to map and visualize the key-information of dissertations in academic libraries. To achieve the aim, an information retrieval system was designed to present the interactive graphic view of dissertations' subjects in academic. Methods: An information retrieval system was designed by information visualization toolkit that presents the related subjects of dissertations in academic libraries. In addition, the satisfaction-levels of library-users were analyzed by administrating a standard questionnaire (QUIS Questionnaire). Results: The study indicated that the designed IR system helped to provide a user-friendly environment through displaying subjective relations of dissertations, overwhelming variety of colors in displaying information. Fast and easy access to the cover-to-cover information of dissertations and userinteraction facilities are the advantages of designed IR. Analysis of data furthermore indicated that the users' satisfaction from the system was from medium to high grade. Conclusion: Designing the IR-system revealed an excessive influence on users' satisfaction; therefore, proposing such systems for employing in academic libraries is very suitable and its implementation is necessary.
\end{abstract}

\section{Keywords}

Information Visualization, Information Retrieval System, Digital Libraries

\section{Introduction}

Information visualization is the study of interactive depictions of abstract data to strengthen the human cognition.

${ }^{*}$ Corresponding author. 
Designing an appropriate information visualization system can be very useful technique for scholars, who intent to get scientific information in digital libraries. Many users in digital libraries usually begin their searches by an unclear vision of what they want to accomplish. If the information retrieval systems can clarify the users' information-needs, and retrieve the proper information, we can announce that a correct search has been performed.

To achieve this purpose, an information retrieval system should provide the translation of user's keywords into controlled vocabulary terms, based on the subject headings of related thesaurus. There is no doubt that choosing the accurate and consistent keywords would provide the possibilities to enhance the content representation and retrieval of related literature.

Using the subject heading of controlled vocabulary is the most important step of retrieving the desired information. It makes reduce the amount of irrelevant results that come up; therefore, selection of the appropriate keywords plays a major role in information retrieving processes.

Other things that may affect the users' satisfaction in using the information retrieval systems are the way of information-displaying, and the simplicity of usage of the system.

The goal of this current paper is to depict the graphically relations between dissertations in order to provide effective subject-based, information retrieval within digital libraries. Keeping in mind that physical access to the underlying digital collection is not an option, efficient subject-based information retrieval is crucial for a successful digital library [1].

A proof of concept is also provided in this study to demonstrate the applicability of the proposed research to current and yet-to-come visual, interactive, and subject-based, information retrieval systems within digital libraries [1].

\section{The Role of Information Visualization in Retrieval Process}

Since the last two decades, several information specialists have paid attention to Human Computer Interaction (HCI) and the user interface design of information retrieval systems, as well as the digital libraries [2].

The study of Daniel Hienert et al. showed that graphics and interaction techniques can be used intuitively and the questions can be answered very fast [3]. One important technique for designing such user-friendly interfaces is information visualization [4].

Information visualization utilizes computer graphics and interaction to assist humans in solving problems [5].

"Information retrieval visualization" refers to the information resources, the user questions, information retrieval model, the retrieval process and the retrieval results of invisible interior semantic relationship convert into graphics or images, and displayed in a two-dimensional, three-dimensional or multidimensional visual space, these intuitive image of spatial information to help users understand the search results, get the retrieval direction to guide the retrieval process, in order to progress the efficiency and performance of information retrieval [6].

Retrieval process visualization can provide information feedback, allow the retrieval process reversible, support retrieval strategy control, and a user's interaction [6].

\section{Information Retrieval Visualization within Digital Libraries}

Information visualization is a set of technologies that use visual computing to strengthen the human cognition with abstract information. However, the major aim of information visualization is to increase the cognitive presentation of information, it should help the human to vast the insights [7]. Examples of websites that have used information visualization technique in their IR systems are: Library of Congress [8]. The National Center for Biomedical Ontology (Bio Portal) [9], Microsoft Academic Search [10], visual thesaurus [11], etc. Medical Subject Headings (MeSH) also visualized [12] [13] and has been used for different purposes.

\section{Proposed Approach}

In academic libraries, Thesis’ sector is special importance, Quick retrieval possibility and awareness of subject relations between thesis and dissertations, is important for students, who want to choose a topic for their dissertation, as well as for researchers, who want to know the results of other researches on a particular topic.

In most Academic libraries, the only way to retrieve thesis information is searching manually or electronically by librarians; On the other hand, not only it doesn't use a particular Subject classification scheme for indexing the thesis, but also it doesn't use the controlled vocabularies in their keywords selection, hence retrieving the 
exact subject of the dissertation is not beyond the realms of possibility. In this study, the information visualization principle was used to retrieve the visualized information of dissertations based on subject areas in digital libraries. We created subject relations between themes based on the subject headings.

In this current proposed system, users can find theses, keywords, supervisors as well as their interesting topics, visually. Users can manage the search-strategy simultaneously between keywords and subjects.

\section{Case Study}

The proposed approach has been applied to the digital library of theses and dissertations in the Management and Medical Informatics Faculty of Tabriz University of Medical Sciences [1]. This IR system provides information via displaying subject relations between various titles of thesis. To design this system, we used the perforce visualization tool, and it is appropriate using by web browsers.

In Section 6 (comparative evaluation) we made a comparative assessment between an ordinary used system (MAKTUB) in the Tabriz University of Medical Sciences and our proposed system. The evaluation showed the major advantage of our designed IR system clearly.

\section{Comparative Evaluation}

In the current IR system of digital library of Tabriz University of Medical Sciences (MAKTUB) (Figure 1) users are able to search in all the libraries of the university or do in a particular college-library.

By typing the keyword (evaluation) in the search box, Results are provided as a list of resources includes the undergraduate, master's and doctoral theses, that the term "evaluation" presents in the part of their bibliographic information. User can find bibliographic details by choosing one of the titles.

Due to lack of subject headings and the lack of Controlled vocabulary in resource indexing, search results for two words ("evaluation" \& "assessment") retrieves different results. And the search results are not subject-based. Furthermore in this system subject relations between these are not visible to users. ${ }^{1}$

\subsection{In Proposed Visual IR System}

In our visual information retrieval system, the disadvantages of the mentioned system have been fixed. The user chooses Management and Medical Informatics Faculty at first. On the first page of software, topics and subjects of all theses and their subject-based correlations will be showed graphically. The information is presented in two separated languages, English and Persian. The user can choose his/her arbitrary language and continue searching.

As typing a word, the system begins to search letter by letter and eliminates the unmatched results and achieves the most relative results finally (see Figures 2-4).

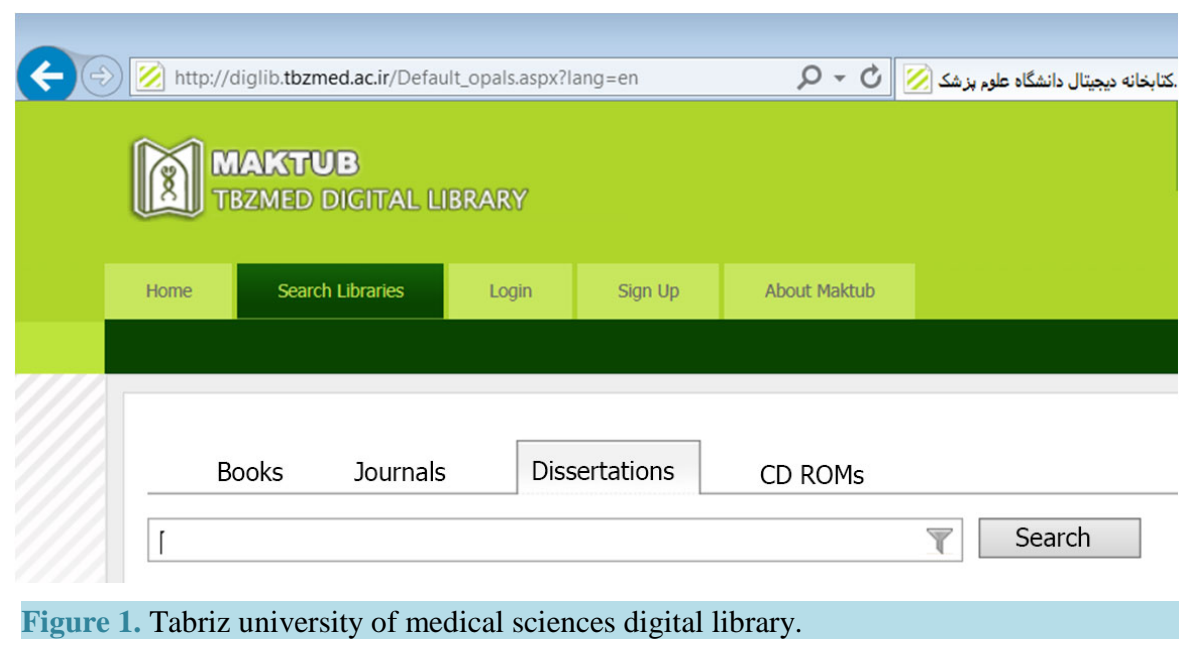

\footnotetext{
${ }^{1}$ In the present application (MAKTUB), the dissertations information is only in Persian, and English language search is not possible, so the search operation has not been show by pictures.
} 


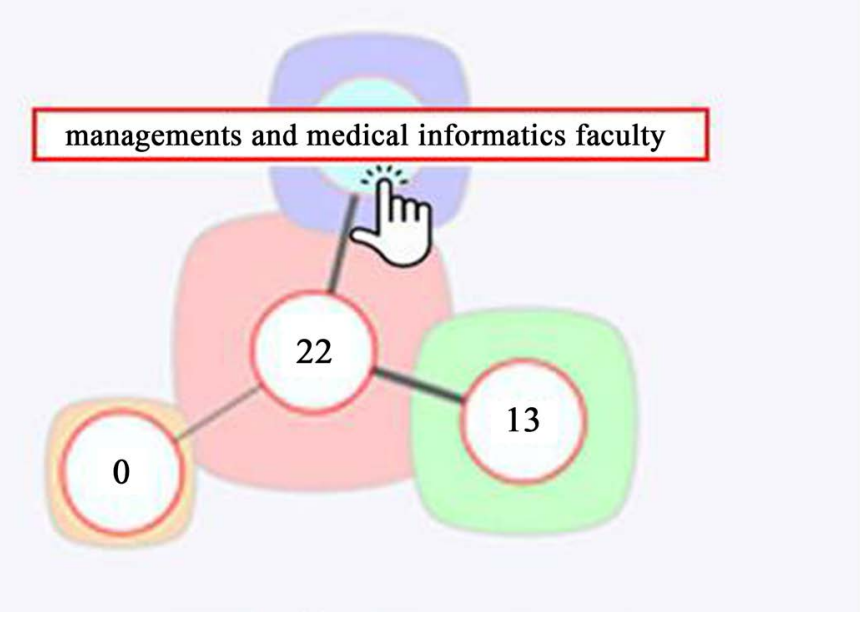

Figure 2. Select health care management department.

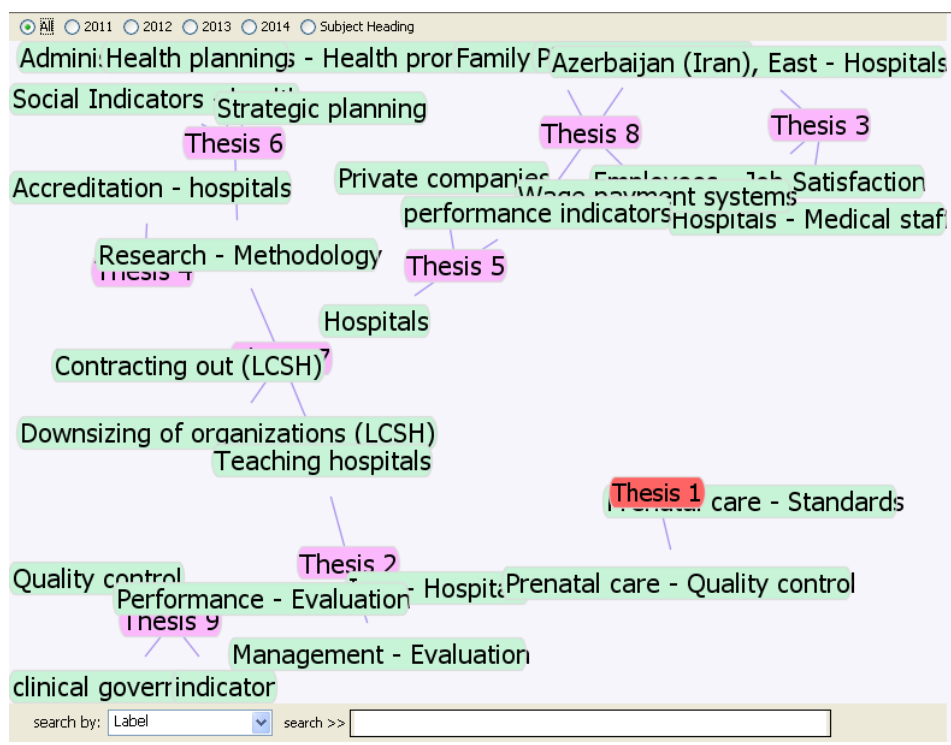

Figure 3. The information presented in English languages.

๑All O 2011 O 2012 O 2013 O 2014 O Subject Heading

\section{Management - Evaluation}

Thesis 2

Performance - Evaluation

Thesis 9

search by: Subject \& Keyword $\vee$ search $\gg$ eVa

Figure 4. The system begins to search letter by letter and eliminates the unmatched results (In English). 


\section{Discussion of Retrieval Information in Proposed Visual IR System}

- Issues devoted to thesis have controlled by using the subject headings.

- The subject headings used to show the relationship between theses to assign the precise subject matter of the thesis.

- Keywords, thesis and masters related to them are shown in the software's interface by moving the cursor on the topics (see Figure 5).

- The system has the ability to search keywords and subject headings assigned to thesis simultaneously, so that searching for two words with same meaning (e.g., evaluation-assessment) similar results retrieves (see Figure 6, Figure 7).

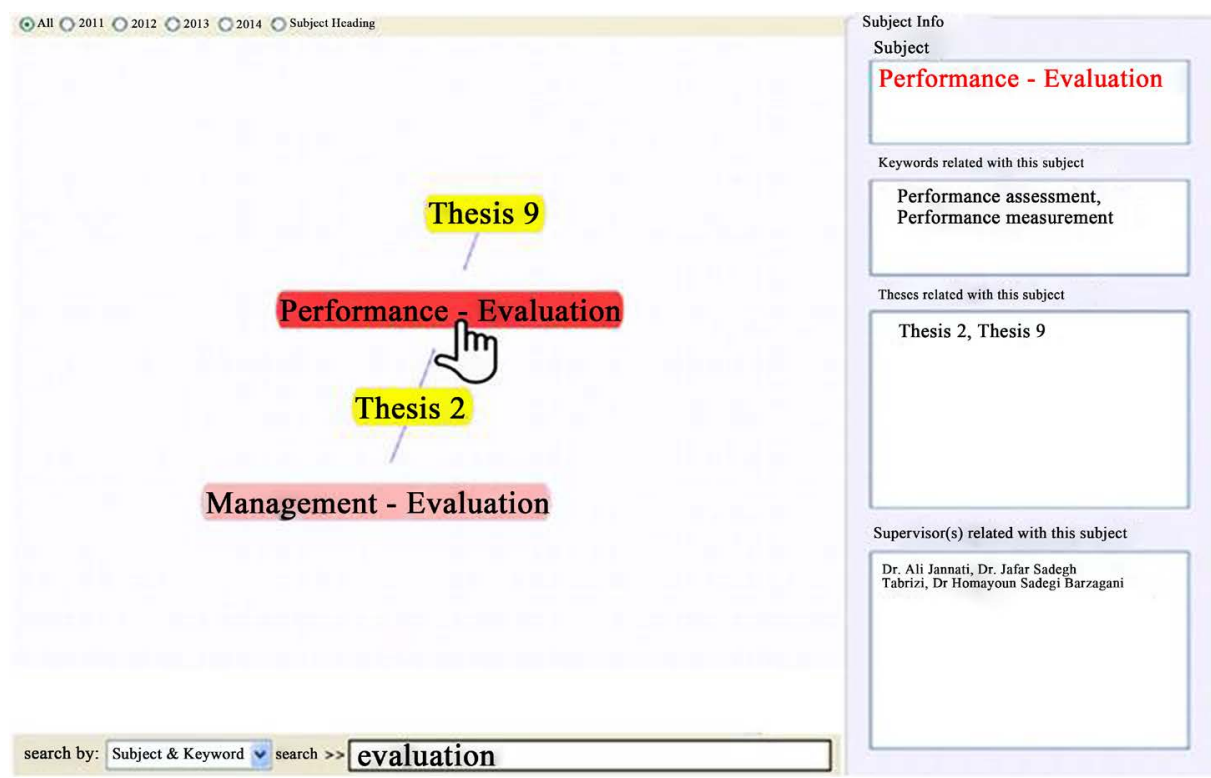

Figure 5. Keywords, thesis and masters related with "performance-evaluation” subject heading are shown in the software's interface by moving the cursor on the topics.

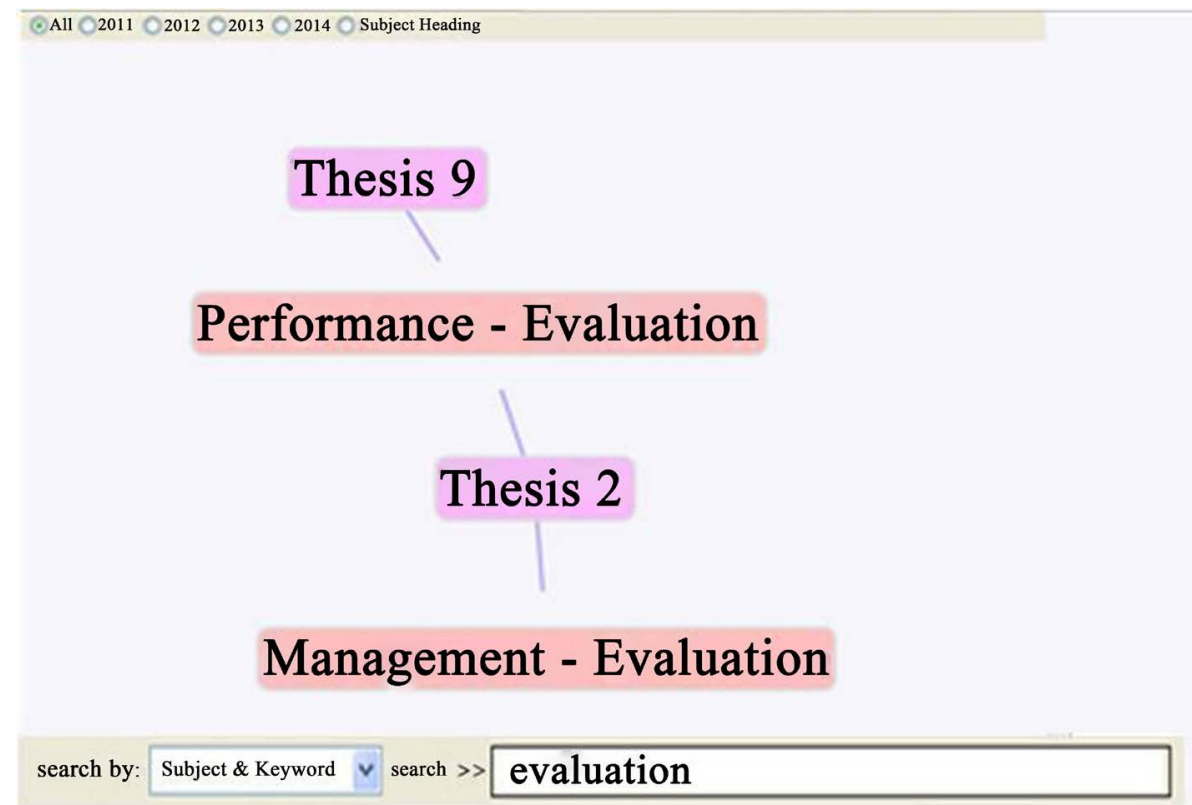

Figure 6. Results have retrieved for "evaluation”. 


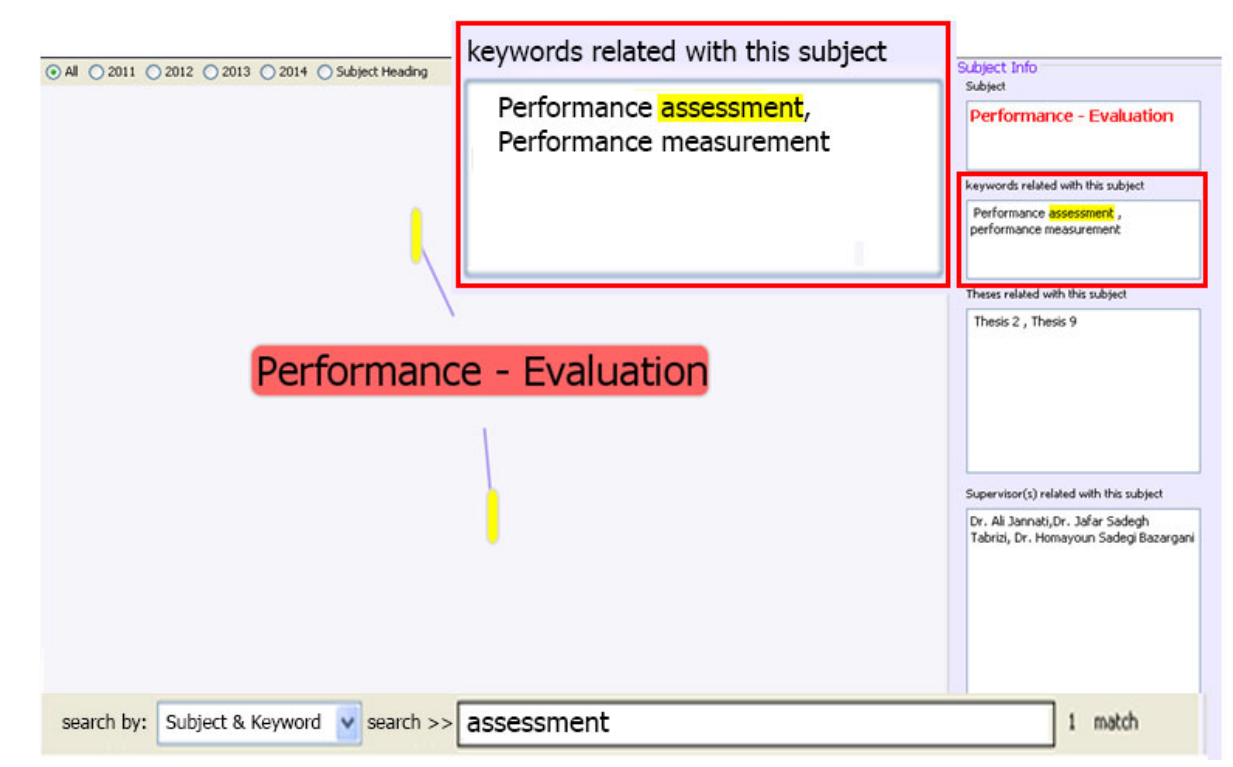

Figure 7. Results have retrieved for “assessment”.

Providing graphical information, possibility of user interaction with the system and displaying the subject relations between the thesis using a graph, has caused to easily diagnose the subject relations with the user, so that the user can assemble information to meet all his/her needs about special subjects.

\section{Conclusion, Future Work}

In this article, an effort is to graphically exploit the relations between dissertations to provide more effective subject-based, information retrieval within digital libraries. Keeping in mind that physical access to the underlying digital collection is not an option, well-organized subject-based information retrieval is crucial for the effectiveness of digital library.

The proposed methodology could be applied to other information resources within digital libraries, thus providing a universal tool for user-centered, interactive, subject-based information retrieval.

During the process, users enhance their cognitive learning, since they are able to discover which subject headings correspond to their information needs.

Future work is oriented towards the exploration of other semantically rich information structures produced by librarians. The ultimate goal of this research is to contribute to the development of next-generation digital libraries capable of exploiting the wealth of knowledge accumulated within traditional libraries [14] [15].

\section{References}

[1] Gerken, J., Heilig, M., Jetter, H.-C., Rexhausen, S., Demarmels, M., König, W., et al. (2009) Lessons Learned from the Design and Evaluation of Visual Information-Seeking Systems. International Journal on Digital Libraries, 10, 49-66. http://dx.doi.org/10.1007/s00799-009-0052-6

[2] Sastry, H.G. and Reddy, L.C. (2009) User Interface Design Principles for Digital Libraries. International Journal of Web Applications, 1, 86-91.

[3] Hienert, D., Sawitzki, F., Schaer, P. and Mayr, P. (2012) Integrating Interactive Visualizations in the Search Process of Digital Libraries and IR Systems. Advances in Information Retrieval, Springer, 447-450. http://dx.doi.org/10.1007/978-3-642-28997-2 38

[4] Wan, G. (2006) Visualizations for Digital Libraries. Information Technology and Libraries, 25, 88-94. http://dx.doi.org/10.6017/ital.v25i2.3335

[5] Ware, C. (2012) Information Visualization: Perception for Design. Elsevier.

[6] Liao, Z., Gao, M. and Yan, F. (2012) Application Study of Information Visualization in Digital Library. National Conference on Information Technology and Computer Science (CITCS 2012), Lunzhou, Atlantis Press, 161-164. http://dx.doi.org/10.2991/citcs.2012.249 
[7] Card, S.K., Mackinlay, J.D. and Shneiderman, B. (1999) Readings in Information Visualization: Using Vision to Think. Morgan Kaufmann.

[8] (2013) Library of Congress Linked Data Service: Authorities and Vocabularies. http://id.loc.gov

[9] Whetzel, P.L., Noy, N.F., Shah, N.H., Alexander, P.R., Nyulas, C., Tudorache, T., et al. (2011) BioPortal: Enhanced Functionality via New Web Services from the National Center for Biomedical Ontology to Access and Use Ontologies in Software Applications. Nucleic Acids Research, 39, W541-W545. http://www.bioontology.org/bioportal http://bioportal.bioontology.org/ http://dx.doi.org/10.1093/nar/gkr469

[10] Microsoft Academic Search. http://academic.research.microsoft.com/

[11] (2013) Visual Thesaurus: Thinkmap, Inc.; 1998-2013. http://www.visualthesaurus.com/

[12] Sheth, N. and Cai, Q. (2003) Visualizing Mesh Dataset Using Radial Tree Layout.

[13] Du, H. and Yoo, T. (2006) Indexing Similarity Visualization over the Medial Subject Headings (MeSH). Report No.

[14] Biglu, M.H. (2008) Scientometric Study of Patent Literature in MEDLINE \& SCI. Doctoral Dissertation, HumboldtUniversitätzu Berlin, Philosophische Fakultät I.

[15] Biglu, M.H. and Askari, O. (2005) A Bibliometric Study of Scientific Output in Tabriz University of Medical Sciences. Proceedings of 10th International Conference of the International Society for Scientometrics and Informetrics (ISSI), Stockholm, 143-156.

\section{Submit or recommend next manuscript to SCIRP and we will provide best service for you:}

Accepting pre-submission inquiries through Email, Facebook, LinkedIn, Twitter, etc.

A wide selection of journals (inclusive of 9 subjects, more than 200 journals)

Providing 24-hour high-quality service

User-friendly online submission system

Fair and swift peer-review system

Efficient typesetting and proofreading procedure

Display of the result of downloads and visits, as well as the number of cited articles

Maximum dissemination of your research work

Submit your manuscript at: http://papersubmission.scirp.org/ 